\title{
A Olimpíada de 2016 no Rio de Janeiro: \\ uma discussão sobre o legado deixado à Vila Autódromo após os jogos
}

http://dx.doi.org/10.21527/2237-6453.2018.45.135-153

Recebido em: 4/4/2017

Aceito: 1이릴

\section{Aline Correia de Sousa Colantuono¹, Gustavo Henrique de Lima Campos²}

\begin{abstract}
RESUMO
Este artigo tem o objetivo de tratar o conceito de legado, especialmente, após a mudança de postura do Comitê Olímpico Internacional (COI) e a transformação da Olimpíada em mercadoria na sociedade do espetáculo, a fim de se compreender o processo de remoções ocorrido na Vila Autódromo, no Rio de Janeiro, para a realização do megaevento. Para tanto, além da introdução e das considerações finais, o trabalho será dividido em quatro seções: na primeira, será apresentado o simbolismo da Olimpíada e a transformação da cidade em mercadoria, notadamente a partir do momento em que o COI mudou de postura e passou a gerir o megaevento como um negócio. Na segunda serão tratadas as contradições observadas no conceito de legado, especialmente após a edição de Sydney, na Austrália, em que se observaram as estratégias de marketing urbano e de máquina de crescimento urbano. Na terceira será mostrado como esse processo ocorreu para a candidatura do Rio de Janeiro à Olimpíada de 2016. Finalmente, na quarta seção, será apresentado o legado do megaevento para a comunidade da Vila Autódromo na capital fluminense.
\end{abstract}

Palavras-chave: Cidade mercadoria. Legado. Marketing urbano. Olímpiada do Rio 2016.

\section{THE 2016 OLYMPICS IN RIO DE JANEIRO: A DISCUSSION ABOUT THE LEGACY LEFT TO VILA AUTÓDROMO AFTER THE GAMES}

\begin{abstract}
This article aims to deal with the concept of legacy, especially after the change of the International Olympic Committee (IOC)'s position and the Olympics' transformation into merchandise in the spectacle's society, in order to understand the process of removals occurred in the Vila Autodromo, in Rio de Janeiro, for the megaevent. Therefore, in addition to the introduction and final considerations, the work will be divided into four sections: in the first, the symbolism of the Olympics will be presented, in particular, from the city's transformation to changes on the IOC's position, when it started managing the megaevent as a business. In the second, the contradictions observed in the concept of legacy will be dealt with, especially after Sydney's edition (Australia), in which urban marketing and urban growth strategies were observed. In the third section, it will be shown how this process occurred for Rio de Janeiro's bid for the 2016 Olympics. Finally, in the fourth section, the legacy of the megaevent will be presented to the Vila Autódromo community.
\end{abstract}

Keywords: City marketing. Legacy. Urban marketing. Olympics 2016 in Rio.

\footnotetext{
${ }^{1}$ Doutoranda em Desenvolvimento Econômico pela Universidade Estadual de Campinas. Mestre em Economia pela Universidade Estadual Paulista. Professora da Faculdade de Tecnologia do Estado de São Paulo (Fatec). alinecsousa@yahoo.com.br

${ }^{2}$ Mestrando em Urbanismo pela Pontifícia Universidade Católica de Campinas. Graduado em Ciências Econômicas pela Pontifícia Universidade Católica de Campinas. gustavoh.lima.campos@gmail.com
} 
Este artigo tem o objetivo de tratar o conceito de legado, especialmente, após a mudança de postura do Comitê Olímpico Internacional (COI) e a transformação da Olimpíada em mercadoria na sociedade do espetáculo, a fim de se compreender o processo de remoções ocorrido na Vila Autódromo, no Rio de Janeiro, para a realização do megaevento.

O trabalho justifica-se pela possibilidade de apresentar as contradições que há no conceito de legado, haja vista a divulgação do bônus e a omissão do ônus à população. Para tanto, não só se utilizará de uma pesquisa explicativa, bibliográfica e qualitativa, como também se pautará nas reportagens veiculadas na grande mídia e em sites governamentais.

Nesse contexto, a partir do sucesso do planejamento urbano para a Olimpíada de Barcelona de 1992, verificou-se a difusão dos modelos de planejamento estratégico no Brasil e na América Latina, pelas agências multilaterais e pelos consultores internacionais, sobretudo os catalães. Os governos locais passaram a pensar as cidades como empresas, visto que ambas estão submetidas aos mesmos desafios e às mesmas condições.

Nesse sentido, Vainer (2011) acredita que o debate atual sobre planejamento substitui a problemática da questão urbana (crescimento desordenado; reprodução da força de trabalho; equipamentos de consumo coletivo; movimentos sociais urbanos; racionalização do uso do solo e outros) pela competitividade urbana (investimento de capital, tecnologia e competência gerencial; atração de novas indústrias e negócios; preço, qualidade dos serviços e força de trabalho qualificada e outros), o que contribui para a transformação da cidade em mercadoria.

Para Arantes (2011), no período recente, a nova geração urbanística não apresenta rupturas significativas com a geração anterior, mas explicita não só um maior gerenciamento empresarial do planejamento, como também o uso mais frequente de políticas orientadas para o mercado. Tudo é negociado nas cidades: desde imagens até itens menos simbólicos.

Assim, uma vez que "[...] o mercado externo e, muito particularmente, o mercado constituído pela demanda de localizações pelo grande capital é o que qualifica a cidade como mercadoria [...]", o que se pergunta é o que, necessariamente, se vende quando se coloca a cidade à venda. Entre os atributos valorizados pelo capital transnacional têm-se os seguintes: "[...] espaços para convenções e feiras, parques industriais e tecnológicos, oficinas de informação e assessoramento a investidores e empresários, torres de comunicação e comércio, segurança..." (VAINER, 2011, p. 79-80).

Uma vez, porém, que as cidades-mercadorias desejam atender a um público consumidor muito específico e qualificado (capital internacional, visitantes e usuários solventes), existe uma grande preocupação, por parte dos planejadores urbanos, com a imagem do ambiente e do entorno social da cidade. Assim sendo, a "[...] 'pobreza urbana e a marginalização', [...], 'condicionam ou influem consideravelmente nas decisões dos agentes econômicos, na atratividade da cidade'” (BORJA; CASTELLS, 1997, p. 133 apud VAINER, 2011, p. 82). 
Sánchez (2010, p. 10) assegura que o marketing urbano associado à promoção de megaeventos, de estádios e de renovação de áreas centrais urbanas com equipamentos culturais está vinculado a custos muito elevados para garantir a posição das cidades-sede. Para a autora, a "[...] crescente midiatização dos megaeventos passa a controlar diversos aspectos da imagem urbana, com impactos nas liberdades civis, no direito à cidade e no direito cidadão de ser visto". Assim, esse modelo de cidade aumenta a desigualdade e compromete as receitas públicas e as políticas sociais, o que estimula os conflitos entre os habitantes.

Desse modo, vive-se a era do culturalismo de mercado na sociedade do espetáculo: ao invés do planejamento convencional quanto aos regulamentos sobre o uso do solo, o planejamento deixou de controlar o crescimento urbano e as cidades passaram a ser máquinas de produzir riquezas. Ou seja, houve uma conversão do planejamento urbano em um ramo cultural da urbanização empresarial, haja vista que a cultura não só é essencial na coalização de classes e interesses, como é responsável pela máquina de crescimento urbano, pois promove o orgulho cívico dos habitantes do lugar e o patriotismo das massas.

Na percepção de Logan e Molotch (1987 apud FERREIRA, 2007, p. 152), nas coalizões organizadas pelas classes rentistas, são envolvidos os proprietários fundiários, os políticos locais, a mídia, as agências de serviços públicos, os setores sindicais, as instituições culturais (museus e universidades), as equipes esportivas e os comerciantes, enfim, todos aqueles que têm a ganhar com o crescimento da cidade. Assim, às elites locais se oferece a possibilidade de produzir a cidade conforme os seus interesses, à medida que se provoca a valorização fundiária, se promovem enormes lucros pessoais e se favorece o crescimento das cidades para o bem de todos. Logo, o poder político dessas coalizões torna as cidades verdadeiras "[...] empresas devotadas ao crescimento da renda agregada através da intensificação do uso do solo urbano". Essa é a máquina de crescimento urbano.

Para fazer das cidades máquinas de crescimento urbano nota-se o uso recorrente dos processos de gentrificação, ou seja, formas de "[...] revitalização, reabilitação, revalorização, reciclagem, promoção, requalificação, até mesmo renascença, e por aí afora, mal encobrindo, pelo contrário, o sentido original de invasão e reconquista, inerente ao retorno das camadas afluentes ao coração das cidades" (ARANTES, 2011, p. 31). Logo, o planejamento estratégico pode ser entendido como um processo legítimo de gentrificação, cuja apropriação do espaço justifica-se pela promoção cultural da cidade.

O processo de espoliação urbana também é um recurso recorrente para se fazer das cidades máquinas de crescimento urbano, visto que se refere à ausência ou à precariedade de serviços de consumo coletivo que, conjuntamente com o acesso à terra, mostram-se socialmente necessários à reprodução urbana dos trabalhadores (KOWARICK, 2000).

Assim, no Observatório das Metrópoles, foi divulgada a seguinte nota sobre o assunto:

O Relator Nacional do Direito à Cidade da Plataforma Dhesca, Orlando Júnior, professor do IPPUR/UFRJ, apresentou durante audiência na Procuradoria Regional dos Direitos do Cidadão, no dia 21 de junho, as conclusões da missão oficial no Rio de Janeiro para acompanhar as denúncias de violação do direito à moradia devido às 
remoções realizadas para a Copa 2014 e Olimpíadas 2016. Segundo ele, a capital fluminense vive um processo perverso de espoliação urbana, com coações, truculêcia e violação dos direitos das comunidades carentes (MEGAEVENTOS, 2011, p. 1).

Por essa razão, será mostrado o caso da Vila Autódromo, ou seja, uma vila de pescadores situada próxima ao bairro da Barra da Tijuca, onde se observou o desenvolvimento urbano fortalecido pelos Jogos Olímpicos. Assim, essa região tornou-se uma preocupação para a realização da Olimpíada 2016 no Rio de Janeiro, visto que sua marginalização poderia interferir na atratividade dos negócios engendrados pelo megaevento.

Conforme Maricato (2013), além de sofrer com o ataque dos capitais internacionais resultantes do processo de globalização, o Brasil foi escolhido como uma economia emergente qualificada para sediar a Copa do Mudo 2014 e a Olimpíada 2016 do Rio. Na percepção da autora, com o advento desses megaeventos, a máquina do crescimento urbano é posta para funcionar no mercado interno, ao legitimar o urbanismo do espetáculo. Esse, contudo, é um gasto inexplicável "[...] em um país que ainda tem enorme precariedade na área da saúde, da educação, do saneamento e dos transportes coletivos" (MARICATO, 2013, p. 45). Assim, enquanto as grandes obras expulsam moradores para viabilizar a expansão imobiliária e a construção do cenário urbano global, parte das obras será subutilizada após a exacerbação de gastos para a sua construção.

Além da introdução e das considerações finais, este artigo será dividido em quatro seções: na primeira será apresentado o simbolismo da Olimpíada e a transformação da cidade em mercadoria, notadamente a partir do momento em que o COI mudou de postura e passou a gerir o megaevento como um negócio. Na segunda serão tratadas as contradições observadas no conceito de legado, especialmente após a edição de Sydney, na Austrália, em que se observaram as estratégias de marketing urbano e de máquina de crescimento urbano. Na terceira será abordado como esse processo ocorreu para a candidatura do Rio de Janeiro à Olimpíada de 2016. Finalmente, na quarta seção, será apresentado o legado do megaevento para a comunidade da Vila Autódromo na capital fluminense.

\section{A ESPETACULARIZAÇÃO DOS JOGOS A PARTIR DA MUDANÇA DE CONDUTA DO COI}

O sucesso obtido com o planejamento urbano de Barcelona, para a Olimpíada de 1992, motivou os gestores de outras localidades, inclusive da América Latina e do Brasil, a aplicarem tal modelo. As cidades passaram a ser pensadas como mercadorias, o marketing urbano tornou-se uma ferramenta importante para promover os espaços urbanos e tudo passou a ser negociado nas cidades, a fim de torná-las máquinas de fazer riquezas. Para compreender esse fenômeno será preciso analisar a evolução histórica do COI e sua mudança de conduta.

O Comitê Olímpico Internacional (COI), fundado em Paris em 1984, por iniciativa do Barão Pierre de Coubertin, teve como objetivo realizar os Primeiros Jogos Olímpicos da Era Moderna. Desde a primeira fase o COI focou seus esforços na criação e no fortalecimento dos principais elementos simbólicos do olimpismo, os quais remetiam aos Jogos da Grécia Antiga. O simbolismo, evocado de forma seletiva, reforçando apenas 
conceitos que agradam à lógica capitalista burguesa, deu apoio para constituir a pretendida autonomia política e jurídica do COI, tornando a marca olímpica uma das mais valorizadas na contemporaneidade.

No decorrer da primeira metade do século 20, as regras publicadas nas cartas olímpicas concentraram-se, basicamente, na estruturação político-administrativa do $\mathrm{COI}$, no funcionamento dos jogos e na criação e fortalecimento dos principais elementos simbólicos do olimpismo. Ou seja:

Segundo o enunciado na Carta Olímpica (IOC, 2011a) é em torno dos valores Olímpicos que se organizam e unificam todos aqueles que participam do Movimento Olímpico. Os princípios da formação moral e união entre os povos através de práticas esportivas, citados como herança das celebrações da Grécia Antiga e da trégua olímpica, foram sintetizados na concepção moderna do "Olimpismo", que se auto representa como filosofia de vida a serviço do desenvolvimento da humanidade (OLIVEIRA, 2012, p. 47).

Os elementos simbólicos do Movimento Olímpico tornaram-se mais elaborados e regulamentados com o intuito de valorizar e criar o sentimento olímpico que serviria, posteriormente, como ferramenta de valorização da marca olímpica. Assim, em 1912, em Paris, foi criado o símbolo olímpico, a bandeira e o lema. Em 1920 a bandeira foi hasteada pela primeira vez e os atletas fizeram o juramento. O lema, expresso por meio de três adjetivos superlativos - isto é: citius, altius e fortius (mais rápido, mais alto e mais forte) - conduzia na direção de um modelo de comportamento socialmente orientado para o sucesso e para a crença no progresso, enfim, para os princípios da sociedade industrial. Os anéis e a bandeira, por sua vez, faziam menção à ideia de união entre os povos evocada pelos Jogos da Antiguidade. A partir desse capital simbólico, o COI fortaleceu o Movimento Olímpico que não apenas se materializou na economia, mas também se viabilizou na supressão da cidade.

Como apontado por Oliveira (2012), esse esforço na constituição do capital simbólico foi ao encontro da lógica empresarial: o COI envolveu-se em uma das maiores pesquisas de mercado do mundo, cujo objetivo era descobrir quais as características que tornavam a marca olímpica especial e quais as principais situações que poderiam pôr em risco o seu valor.

Nos Jogos de Berlim, em 1936, além da entrada da transmissão televisiva, destacou-se o esforço alemão em demonstrar ao mundo o poder socioeconômico da ditadura nazista com o intuito de realizar a maior Olimpíada, até então, em termos de instalações, organização, público, cobertura jornalística, etc., contudo,

enquanto disfarçava a violência de suas políticas racistas e seus planos de expansão territorial, removendo temporariamente painéis antissemitas ou abrandando a cruel retórica contra judeus e ciganos na imprensa, no período imediatamente anterior e durante os jogos, o regime nazista utilizava a imagem dos esportistas alemães para promover o mito da "superioridade racial", da estética e do "valor físico" dos arianos (OLIVEIRA, 2012, p. 52).

Ademais,

tal acontecimento, juntamente com a iniciativa de Los Angeles de buscar o desenvolvimento através da realização do evento, põe em evidência três novas situações que viriam interferir definitivamente nas relações entre a produção do espetáculo 
esportivo e a produção da cidade. A primeira delas é a descoberta do potencial de mobilização de capitais políticos e econômicos. A segunda, consequente da primeira, a indicação ao Movimento Olímpico da possibilidade de utilizar esse potencial para seduzir governantes de cidades e países à disputa pelo direito de sediar os eventos e de, nessa condição, converter tal disputa em benefício próprio ou de interesses por ele representados. A terceira e última novidade foi o grande passo ensaiado na direção à espetacularização, com a construção de instalações de grande porte, alcance de grande público e, especialmente, a transmissão televisiva que veio produzir uma completa reconfiguração do campo e de sua relação com outros campos e com a cidade (OLIVEIRA, 2012, p. 53).

Após dois períodos sem a realização das Olimpíadas, devido à ocorrência da Segunda Guerra Mundial, os Jogos Olímpicos voltaram a acontecer em 1948, na cidade de Londres, porém com maior capacidade de atrair o interesse de governantes, de empresas e de atletas. Já nos Jogos Olímpicos de 1952, em Helsinque, na Finlândia, foi fechado o primeiro contrato bem-sucedido de transmissão televisiva, em que foram firmados os primeiros acordos de bens e serviços e o primeiro programa de comercialização internacional, todos sob o controle do Comitê Organizador dos Jogos Olímpicos (Cojo). Nesse sentido, dando continuidade ao processo da espetacularização, foi nos Jogos Olímpicos de 1960, em Roma, que foi dada a entrada definitiva da televisão, quando o evento foi transmitido para 18 países europeus, além dos Estados Unidos, do Canadá e do Japão (OLIVEIRA, 2012).

Nesse momento, no entanto, ainda existia dentro do COI uma tensão entre os princípios idealistas e os comerciais da filosofia olímpica moderna, bem como a necessidade de sustentar, financeiramente, o maior evento atlético e de mídia do planeta. Nesse sentido,

a chave utilizada para resolver o paradoxo foi promover e tornar hegemônica dentro do Movimento Olímpico a ideia de que era perfeitamente possível conciliar o mercado que o sustenta e os valores morais do olimpismo. Isto foi alcançado através de um revolucionário programa de marketing que se apoia fundamentalmente em duas estratégias: de um lado, o controle centralizado da venda do direito de exclusividade para a transmissão televisiva em cada território do mundo; de outro lado, a venda do direito exclusivo, por categoria de produto, de associar uma determinada marca à marca olímpica. Nesse programa, que constitui uma das maiores viradas da história do mundo empresarial, a mercadoria mais valorizada é exatamente o conjunto de valores não comerciais associados ao olimpismo (OLIVEIRA, 2012, p. 68).

Desde então, os Jogos Olímpicos passaram a apreciar um conjunto de atributos valorizados pelo marketing, tais como: a honra, a integridade, a determinação e o compromisso com a excelência, ou seja, qualidades, inerentemente, destacadas por empresas. A entrada de patrocinadores formou um dos alicerces que viabilizam o acontecimento das Olimpíadas e impulsionam a necessidade de jogos cada vez mais grandiosos e espetaculares. A associação dessas empresas aos Jogos tem como objetivo básico a valorização delas mesmas; o COI agora assume o compromisso de assegurar todo esse processo. 
Para acontecer a espetacularização, contudo, falta a existência do compromisso de um novo parceiro para aderir ao Movimento Olímpico e, assim, produzir megaeventos cada vez mais grandiosos. A responsabilidade não recai mais diretamente no COI, mas no local em que são realizados os Jogos Olímpicos, ou seja, nas cidades. Estas, por sua vez, utilizam-se dos megaeventos não somente para valorizar determinados espaços urbanos e favorecer as coalizões entre as diferentes classes sociais, mas também para satisfazer à demanda de seu principal mercado, ou seja, o capital internacional, os visitantes e os usuários solventes.

Isso posto, de acordo com Vainer (2003), desde o final de 1980 e ao longo dos anos 90, em um mercado internacional extremamente produtivo e competitivo, as cidades passaram a ser pensadas como empresas. Foi levado em conta, portanto, que o planejamento das cidades, como o de qualquer empresa, deveria ser entregue àqueles que entendem de negócios, ou seja, aos empresários. Desse modo,

a cidade-empresa tem de ser conduzida como uma empresa. Ora, uma empresa não é lugar de democracia. Possui um comando claro: o detentor do capital. Seus trabalhadores não são contratados para discutir ou opinar sobre o que deve fazer uma empresa. [...]. A cidade-empresa-mercadoria-negócio é, pois, necessariamente, uma cidade de onde deve ser banido todo conflito, toda discussão. A cidade deve estar unida para competir (VAINER, 2003, p. 29).

Nesse sentido, nas agências multilaterais, tal como no Banco Mundial, sugere-se que as cidades disputem não só os investimentos de capital, tecnologia e capacidade empresarial, mas igualmente a atração de novos negócios e de mão de obra qualificada. Ademais, elas devem ser competitivas tanto na qualidade como no preço dos serviços prestados à sociedade.

Além disso, subordinados aos interesses do capital imobiliário, os governos locais são estimulados a investir em projetos de revitalização ou em obras monumentais, a fim de valorizar áreas, geralmente já valorizadas, promover lugares específicos e vender a imagem construída da cidade para um determinado público-alvo. Por conseguinte, "[...] o discurso da gestão urbana empresarial vem se firmando em todas as escalas de poder e gera práticas de administração das cidades cada vez mais preocupadas em fixar uma imagem publicitária que venda o seu produto-cidade" (COSTA, 2010, p. 153).

Logo,

os espaços capturados pelas relações de produção capitalista, que são incorporados aos processos de reestruturação urbana em curso, podem se destinar à produção ou propriamente ao consumo do espaço. No primeiro caso, por intermédio de obras de infraestrutura, operações logísticas de otimização de fluxos produtivos e obras de modernização tecnológica que agregam densidade técnica aos lugares para atração de empresas multinacionais; no segundo, por meio de operações vinculadas ao turismo e ao lazer, operações imobiliárias e, finalmente, operações voltadas ao consumo da cidade, estimuladas pela publicidade (SÁNCHEZ, 2010, p. 20).

Os grandes projetos urbanos, culturais e esportivos vêm sendo formulados, no âmbito das políticas urbanas neoliberais, com a intenção de integrar simbolicamente a cidade e envolvê-la em uma política-espetáculo. Trata-se, portanto, de um "[...] poder crescente que leva cidades a lutar pela obtenção do direito de sediar tais eventos, to- 
mados como incontestável alavanca para a dinamização da economia local e, sobretudo para redefinir a imagem da cidade no competitivo cenário mundial" (MASCARENHAS, 2014, p. 54).

Voltando à lógica do $\mathrm{COI}$, destaca-se a profunda reestruturação urbana de Barcelona, em 1992, e como ela criou um novo paradigma de modelo de desenvolvimento, aumentando as disputas pelos jogos e elevando a mobilização de capitais econômicos relacionados ao projeto olímpico a um novo patamar.

Nesse contexto, de acordo com Sánchez (2010, p. 10), o governo brasileiro e, principalmente, a cidade do Rio de Janeiro, vem demonstrando interesse em atrair grandes competições esportivas internacionais desde os anos 90, o que resultou na conquista do direito de sediar os Jogos Pan-Americanos Rio 2007, a Copa do Mundo 2014 e os Jogos Olímpicos Rio 2016. Para a autora, "[...] as coalizões de atores (governamentais, privados e de agências internacionais) vinculados, por exemplo, ao projeto olímpico, percebem e se utilizam do megaevento, um espetáculo em escala mundial, para chamar para si a atenção internacional, redirecionar investimentos e amalgamar um novo projeto hegemônico".

As reivindicações dos diversos agentes econômicos para a realização de megaeventos, como a Olimpíada 2016, foram tratadas no Brasil como se fossem desejadas pela sociedade como um todo na busca de um legado para a nação. Enquanto os gestores públicos, por meio das estratégias de marketing urbano, buscaram divulgar a imagem do país no exterior, a fim de atrair mais turistas e mais negócios ao mercado interno; os capitais imobiliários e financeiros encontraram um cenário favorável com a realização dos Jogos para valorizar ainda mais os seus ativos. Esse mecanismo será mais bem compreendido na próxima seção, ao se analisar o conceito de legado que foi herdado da edição olímpica de Sydney, na Austrália.

\section{O LEGADO DEIXADO PELOS MEGAEVENTOS: UMA NOVA PERSPECTIVA APÓS OS JOGOS OLÍMPICOS DE SYDNEY}

A ideia de legado deixado à população pela realização de megaeventos esportivos (Copa do Mundo/Olimpíadas) é uma forma de atrair a candidatura das cidades-anfitriãs que não apenas se submetem às exigências técnicas dos padrões normativos internacionais, como também apostam na concepção de projetos arquitetônicos que interfiram no espaço urbano.

Em 2001, o COI constituiu uma comissão que estabelecia recomendações para gerir a complexidade e os custos do evento olímpico. Entre as 117 recomendações publicadas no relatório, encontra-se a ideia de separar os custos operacionais do evento, que pertencem ao orçamento Cojo, dos custos ligados aos investimentos em infraestrutura e instalações, considerados orçamento não Cojo, que ficariam como legado para o país e para as cidades-sede das Olimpíadas.

Após a realização dos Jogos Olímpicos de Sydney, surgiu uma nova obrigação imposta às cidades candidatas a sediar os Jogos: o compromisso com o legado. A tentativa de promoção das duas vertentes de legados, os tangíveis e os intangíveis, tem sido o principal argumento apresentado para a concorrência das cidades aos megaeventos. 
Nesse contexto, como define Oliveira (2012), legados tangíveis referem-se aos recursos aportados, a partir de outras esferas de governo ou da iniciativa privada nas cidades- anfitriãs, que se convertem em reestruturação urbana e em instalações esportivas. Além disso, são apontados como legados tangíveis: (i) os efeitos sobre o emprego, como consequência do próprio evento; (ii) o temporário boom na indústria da construção civil, provocado pelos investimentos e (iii) o incremento na indústria do turismo, promovido com a projeção das mídias nacional e internacional que divulgam o evento. Por sua vez, os legados intangíveis são relacionados ao city marketing, incluindo não só a capacidade de se criar uma imagem positiva da cidade e do país anfitrião, bem como de aumentar o orgulho cívico de seus habitantes ou fortalecer a sua identidade com o megaevento.

Segundo Mascarenhas (2014), os gestores públicos visam ao desenvolvimento do turismo e à expansão da visitação com as Olimpíadas, enquanto as intervenções urbanísticas preestabelecidas pelo $\mathrm{CO}$ vislumbram: (i) os investimentos em instalações que atendam às diversas modalidades esportivas; (ii) o alojamento dos atletas, do pessoal de apoio, dos membros dos Comitês Olímpicos e da imprensa e (iii) as melhorias na infraestrutura geral das localidades que acolhem esses eventos (transportes, telecomunicações, malha viária e outras).

Criado, portanto, a partir do know-how do Comitê Organizador de Sydney, para os Jogos Olímpicos de 2000, e de entidades e empresas relacionadas ao COI, o programa Transfer of Olympic Knowledge (TOK) foi desenvolvido a fim de propiciar as bases para a sustentação das Olimpíadas. Ademais, o referido Comitê concebeu a Olympic Games Knowledge Services (OGKS), com sede na Suíça e cuja direção era feita por Craig Mclatchey, ex-secretário geral do Comitê Olímpico Australiano e proprietário da Events Knowledge Services (EKS), primeira empresa de consultoria especializada exclusivamente na produção de eventos. Nesse contexto, Oliveira (2012, p. 115) faz a seguinte afirmação:

A OGKS ajuda o COI no desenvolvimento do programa TOK através de sistemas de adição e transferência de conhecimentos "implícitos e explícitos" e possui, dentre suas funções, as de fomentar e induzir candidaturas, bem como identificar e credenciar experts com "experiência e perícia relevantes" na organização de Jogos para dar consultoria para organizadores de evento e cidades candidatas.

Assim entendido, em todas as candidaturas com chances de vitória, encontra-se a presença dos mesmos grupos de consultoria que, ao lado das instituições internacionais responsáveis pela organização e normatização dos eventos, produz dossiês padronizados, a fim de tornar a decisão da disputa pariforme, se for baseada estritamente no critério técnico. Logo, projetos de candidaturas são coordenados por instituições privadas, desprezando as necessidades do conjunto da sociedade, mas com o objetivo de conciliar os interesses daqueles que lhes dão suporte.

É importante ressaltar que a disputa costuma ser acirrada entre as cidades candidatas a um megaevento como os Jogos Olímpicos. Para ter um projeto vencedor, os governos locais prometem construir obras monumentais, que alteram a paisagem urbana. Para executá-las, alianças são estabelecidas entre o Estado, o capital imobiliário e as grandes empreiteiras, o que leva aos recorrentes processos de valorização da terra e de gentrificação. Esse mecanismo é reconhecido na literatura por redes de crescimento. 
Conforme Gottdiener (1997), as redes de crescimento referem-se às coalizões realizadas entre as entidades públicas e os agentes privados, por meio da articulação dos arranjos particulares existentes no ambiente construído, a fim de se atender às reivindicações de determinados grupos sociais como se elas fossem desejadas pela sociedade. Nesse contexto, os governos locais dependem do crescimento econômico engendrado por essa negociação favorável, enquanto determinados segmentos atendem aos seus próprios interesses (ideológicos, políticos, econômicos e culturais) em prol do virtual benefício à coletividade.

Para tanto, há um empenho promovido pelas elites locais para que as cidades prosperem por meio do desenvolvimento urbano, visto que esses espaços são pensados como mercadorias cujos preços são determinados por compradores que buscam maximizar seus ganhos individuais. Esses interesses são canalizados no âmbito das redes de crescimento, por meio da execução de empreendimentos específicos, o que estimula a valorização imobiliária. Nesse contexto, a cidade torna-se uma máquina de crescimento urbano, isto é, em seu meio é realizado o planejamento sobre o uso e a ocupação do solo por meio de alianças entre profissionais do mercado imobiliário local e outros agentes para promover o seu desenvolvimento urbano (LOGAN; MALOTCH, 1987; GOTTDIENER, 1997).

Costa (2010) assegura que o marketing urbano é uma alternativa ao planejamento estratégico, por meio do qual se cria uma imagem da cidade para vendê-la ao mercado externo. Nessa perspectiva, ao invés de um espaço de construção social de seus próprios habitantes, a cidade torna-se um negócio e passa a ser administrada como uma empresa.

Analogamente, Vainer (2011) afirma que o emprego do marketing urbano ocorre em um mercado extremamente competitivo, cujas cidades estão à venda e cujos prefeitos agem como vendedores ambulantes, ao invés de atuarem como dirigentes políticos. Dessa forma,

as construções de complexos turísticos e de lazer, centros de exposição, museus, shopping-centers, revitalização de centros históricos, além da realização de grandes eventos com seus ícones arquitetônicos e seus recintos de consumo exclusivo e hedonista, são intervenções que compõem o repertório de ações do modelo empreendedorista, acentuando a competição entre cidades no cenário global (MASCARENHAS, 2014, p. 54).

Ademais, uma das razões que leva cidades a lutar pela obtenção do direito de sediar os megaeventos é a magnitude crescente da poderosa aliança mídia-esporte-negócios, "[...] que articula a promoção global do evento a partir de milionários contratos televisivos e patrocínio de grandes marcas comerciais, interessadas na ampla visibilidade internacional proporcionada pelo espetáculo esportivo" (MASCARENHAS, 2014, p. 54). Assim, sediar eventos esportivos é um meio de dinamizar a economia local e de redefinir a imagem da cidade no competitivo cenário mundial.

Isso posto, na próxima seção será abordado o processo de candidatura do Rio de Janeiro aos Jogos Olímpicos de 2016, levando em consideração a discussão apresentada sobre legado, máquina de crescimento urbano, redes de crescimento e marketing urbano. 


\section{O PROCESSO DE CANDIDATURA DO RIO DE JANEIRO À OLIMPÍADA DE 2016}

De acordo com Proni, Faustino e Silva (2014), desde 1984 o Comitê Olímpico Internacional (COI) transformou as Olimpíadas em um projeto de marketing sofisticado, a fim de gerar lucros milionários aos seus organizadores, contudo não apenas os custos para a realização dos jogos aumentaram significativamente, com o intuito de tornar o evento ainda mais grandioso, mas também as exigências quanto ao padrão de qualidade nos serviços urbanos prestados nas cidades-anfitriãs se intensificaram bastante. Assim, enquanto as receitas do marketing olímpico servem para pagar as despesas com a organização do megaevento, as cidades-sede devem arcar com os demais gastos para a preparação do local da festa.

Embora a candidatura para um evento desse porte esteja se tornando cada vez mais dispendiosa, os possíveis anfitriões estão convencidos da viabilidade do negócio, uma vez que os benefícios esperados, em termos de legados, na percepção dos candidatos, compensam os esforços e sacrifícios requeridos.

Desse modo, na esperança de obter legados tangíveis (progressos na economia do país; na infraestrutura esportiva; na mobilidade urbana; na segurança e na qualidade ambiental) e legados intangíveis (melhorias na imagem da nação no exterior, no conhecimento e na cultura), visando ao reposicionamento da cidade-sede na rede global, as candidaturas tornam-se mais caras e competitivas. Nesse sentido, Bottura (2014, p. 128) afirma o seguinte:

[...] a fase de profissionalização dos Jogos Olímpicos coincide com o período histórico correspondente à globalização da economia. Nesse momento, a intrínseca relação dos megaeventos com o panorama político e econômico global não apenas se reafirma como também assume proporções jamais registradas na história. 0 paulatino crescimento nas dimensões da espetacularização e no montante de recursos mobilizado para a realização das Olimpíadas vem proporcionando uma completa distorção dos princípios e valores olímpicos defendidos por Pierre Coubertin (criador dos Jogos Olímpicos Modernos), no começo do século XX. Da intenção de apresentar-se como celebração da paz entre nações por meio da competição esportiva, o evento transformou-se em desculpa esportiva para a celebração da competitividade entre cidades globais.

Nesse contexto, alianças entre o capital imobiliário e a gestão urbana local são formalizadas para fazer das cidades máquinas de crescimento. Para tanto, os prefeitos não só vendem à sociedade a ideia de desenvolvimento urbano engendrado da realização de empreendimentos específicos que atendam às necessidades dos megaeventos, como asseguram um benefício coletivo decorrente da promoção desses grandes projetos urbanos, culturais e esportivos. Assim, as coalizações formadas no âmbito das redes de crescimento visam a dinamizar a economia local e redefinir a posição da cidade-sede no cenário mundial, por meio da valorização imobiliária obtida com a promoção desses eventos.

Para que a sociedade se beneficiasse com os megaeventos, contudo, não só seria importante evitar que as obras de infraestrutura urbana ficassem desconectadas de um planejamento estratégico de longo prazo, como também seria necessário que os programas sociais fossem providenciados para incluir segmentos desprivilegiados da socie- 
dade, o que não foi feito com a Vila Autódromo, alvo de análise na próxima seção. Para tanto, seria preciso que a atuação do Estado não fosse pautada apenas no atendimento dos interesses imediatos de grupos sociais privados, cujas políticas públicas conduzissem à instauração de uma cidade de exceção, na qual prevalece a democracia do capital (VAINER, 2011, p. 12).

Em maio de 2007, Baku (Azerbaijão), Doha (Qatar), Praga (República Tcheca), Chicago (Estados Unidos), Madrid (Espanha), Rio de Janeiro (Brasil) e Tóquio (Japão) lançaram suas propostas ao COI para sediarem a Olimpíada em 2016. Em junho de 2008 somente as quatro últimas cidades continuaram na disputa.

Para candidatar-se aos Jogos Olímpicos de 2016, o Rio de Janeiro não só desembolsou mais de R\$ 88 milhões, como apresentou o projeto mais caro (US\$13,9 bilhões) entre as quatro cidades finalistas, cuja maior parte seria financiada pelos governos federal, estadual e municipal. O projeto estava centrado em dois eixos: i) inclusão social, juventude, esporte e educação e ii) regeneração urbana e meio ambiente. Enquanto previa-se o gasto de US\$11,1 bilhões nas obras de infraestrutura urbana (transporte, saneamento, energia, segurança, hospedagem e núcleo olímpico), pretendia-se despender US\$ 2,8 bilhões com as instalações esportivas e as funções operacionais do evento (centro de imprensa, Vila Olímpica e outras) (PRONI; FAUSTINO; SILVA, 2014).

Em 2009 o COI elegeu o Rio de Janeiro, com 66 dos 98 votos, para sediar a Olimpíada de 2016. Entre os argumentos proferidos pelo ex-presidente Luiz Inácio Lula da Silva para tornar a capital carioca a cidade vencedora estavam: (i) a identidade da população brasileira, por se tratar de um povo de misturados que exala alegria, calor e paixão e (ii) a flexibilidade nacional, pela boa convivência com o diferente, ou seja, requisitos compatíveis com os ideais olímpicos. Além disso, o ex-presidente do Banco Central, Henrique Meirelles, apresentou argumentos econômicos, políticos e sociais favoráveis à candidatura do país, enquanto o ex-prefeito Eduardo Paes e o ex-governador Sérgio Cabral mostraram a viabilidade estratégica da candidatura do Rio de Janeiro para o desenvolvimento da cidade e do Estado (LIRA, 2010).

Entre as obras e os custos previstos para a realização da Olimpíada do Rio de Janeiro 2016 encontram-se as informações relacionadas nos Quadros 1 e 2 a seguir. Nota-se que as obras previstas concentraram-se em intervenções urbanísticas exigidas pelo COI, isto é, instalações esportivas, alojamento e transporte urbano, além da necessidade de intensificar a segurança. Ademais, a construção de equipamentos urbanos novos mostrou-se inevitável, ainda que se utilizassem aqueles já prontos.

Quadro 1 - Obras previstas e locais das instalações para a Olimpíada do Rio de Janeiro 2016: instalações esportivas, alojamento, transporte e segurança

\begin{tabular}{|c|c|c|}
\hline 36 - Instalações Esportivas & Alojamento & \multirow{4}{*}{$\begin{array}{c}\text { Transporte Urbano: criação de anel } \\
\text { de alta capacidade, que inclui qua- } \\
\text { tro linhas de ônibus e três linhas de } \\
\text { metrô }\end{array}$} \\
\hline $10-$ prontas & 13 mil quartos de hotel & \\
\hline $8-$ reformadas & \multirow{2}{*}{$\begin{array}{c}25 \text { mil quartos em vilas cons- } \\
\text { truídas }\end{array}$} & \\
\hline 9- construídas & & \\
\hline 9-temporárias & 1,7 mil apartamentos & \multirow{2}{*}{$\begin{array}{l}\text { Segurança: "bolsa olímpica" para } \\
\text { complementar o salário policial e } \\
\text { para a reurbanização de favelas }\end{array}$} \\
\hline $\begin{array}{l}\text { Local: } 4 \text { zonas da cidade - Barra, } \\
\text { Copacabana, Maracanã e Teodoro }\end{array}$ & $\begin{array}{l}8,5 \text { mil quartos em navios de } \\
\text { cruzeiro ancorados no porto }\end{array}$ & \\
\hline
\end{tabular}

Fonte: Elaborado pelos autores a partir de PRONI; FAUSTINO; SILVA (2014, p. 135-136). 
Em agosto de 2013 o orçamento previsto foi reajustado para $\mathrm{R} \$ 31,179$ bilhões divididos em $\mathrm{R} \$ 15,589$ bilhões para mobilidade urbana, $\mathrm{R} \$ 9,795$ bilhões em obras de revitalização e infraestrutura, $R \$ 2,783$ bilhões com instalações esportivas e $R \$ 3,012$ bilhões com projetos de despoluição e outros compromissos (ver Quadro 2).

Conforme Lima, Takaki e Sousa Colantuono (2016), porém, em março de 2014 o total dos investimentos para a realização da Olimpíada Rio 2016 já estava estimado em $\mathrm{R} \$ 36,7$ bilhões; enquanto, em agosto de 2016 , o orçamento previsto subiu para $\mathrm{R} \$ 38,3$ bilhões.

Quadro 2 - Estimativa do custo dos investimentos para a Olimpíada do Rio de Janeiro 2016

\begin{tabular}{|c|c|c|c|}
\hline Tema & Obra & Custo (em $\mathrm{R} \$$ ) & Responsável \\
\hline \multirow{7}{*}{ Transporte } & BRT Transoeste & 900 milhões & Prefeitura \\
\hline & BRT Transcarioca & 1,6 bilhão & Prefeitura \\
\hline & BRT Transolímpica & 1,5 bilhão & Prefeitura/PPP* \\
\hline & BRT Transbrasil & 1,5 bilhão & Prefeitura \\
\hline & VLT do Centro & 1,1 bilhão & Prefeitura/PPP* \\
\hline & Reforma do Elevado do Joá & 489 milhões & Prefeitura \\
\hline & Linha 4 do Metrô & 8,5 bilhões & Governo do Estado/PPP* \\
\hline \multirow{5}{*}{ Infraestrutura } & Reforma do Porto & 314 milhões & Governo Federal \\
\hline & Revitalização da Região Portuária & 8,3 bilhões & Prefeitura/PPP* \\
\hline & Porto Olímpico & 575 milhões & Prefeitura/PPP* \\
\hline & Controle de Enchentes & 292 milhões & Prefeitura \\
\hline & Viaduto Abolição & 314 milhões & Prefeitura \\
\hline \multirow{4}{*}{$\begin{array}{l}\text { Instalações } \\
\text { Esportivas }\end{array}$} & Parque Olímpico & 1,35 bilhões & Prefeitura/PPP* \\
\hline & Centro de Tênis & 183 milhões & Prefeitura \\
\hline & Campo de Golfe & 60 milhões & Prefeitura/PPP* \\
\hline & $\begin{array}{l}\text { Reforma do Sambódromo } \\
\text { (arco e flecha) }\end{array}$ & 65 milhões & Prefeitura \\
\hline \multirow{4}{*}{$\begin{array}{l}\text { Outros Compro- } \\
\text { missos }\end{array}$} & $\begin{array}{c}\text { Despoluição da Baía de Guanabara, } \\
\text { Lagoa Rodrigo de Freitas e Lagoas da } \\
\text { Barra }\end{array}$ & 2 bilhões & Governo do Estado \\
\hline & Despoluição da Bacia de Jacarepaguá & 362 milhões & Prefeitura \\
\hline & Parque dos Atletas & 40 milhões & Prefeitura \\
\hline & Centro de Operações & 25 milhões & Prefeitura \\
\hline Total & - & 31,179 bilhões & - \\
\hline
\end{tabular}

Fonte: Adaptado de PRONI; FAUSTINO; SILVA (2014, p. 139). (*) PPP = Parceria Público-Privada.

É importante ressaltar que a maioria das obras realizadas no Rio de Janeiro para a Olimpíada teve financiamento público, seja da prefeitura, do governo do Estado ou da União, porém muitas delas tiveram a participação de Parcerias Público-Privadas (PPP).

Nesse contexto, Vainer (2011) assegura que o novo modelo de planejamento estratégico enfatiza grandes projetos de desenvolvimento urbano cujos empreendimentos, normalmente, são elaborados por PPP, acompanhados de desregulamentação, de concessão de vantagens fiscais e de privatização dos espaços urbanos, ou seja, medidas que interessam, especialmente, à democracia do capital.

Uma vez que os legados deixados por megaeventos esportivos, tais como as Olimpíadas, são usados como argumentos à população para justificar não só os processos caros de candidatura, bem como as obras monumentais concebidas a partir de alianças estabelecidas entre Estado, capital imobiliário e grandes empreiteiras, a imagem do en- 
torno social da cidade preocupa os planejadores urbanos, visto que influencia tanto nas decisões dos agentes como na atratividade do local. Assim, a Vila Autódromo tornou-se uma preocupação para a realização da Olimpíada 2016 no Rio de Janeiro, visto que sua marginalização poderia interferir nos negócios engendrados pelo megaevento. Esse assunto será tratado a seguir.

\section{AS REMOÇÕES DE MORADORES DA VILA AUTÓDROMO OCORRIDAS COM O ADVENTO DOS JOGOS OLÍMPICOS 2016 RIO NO RIO DE JANEIRO}

A Vila Autódromo, inicialmente uma pequena vila de pescadores, é símbolo de resistência das ameaças de remoção promovidas pela sinergia de interesses entre os setores público e privado. Situada próxima ao bairro da Barra da Tijuca, encontra-se no meio ou no caminho do desenvolvimento urbano fortalecido pelos Jogos Olímpicos. Esse megaevento foi apontado como elemento central para estabelecer a Barra da Tijuca como a nova centralidade da cidade do Rio de Janeiro pelos empresários da região, presentes no bairro desde a década de 80. A Olimpíada tornou-se o principal argumento da prefeitura da cidade para a remoção da Vila Autódromo. O símbolo do evento esportivo reforçou a pressão exercida sobre os moradores do local, pois eles não deveriam se opor ao contraditório legado com que a cidade do Rio de Janeiro foi agraciada.

Consolidada como espaço de expansão imobiliária no momento de transição entre o modelo de planejamento urbano, fundado no modernismo funcionalista, para o planejamento estratégico, a Barra da Tijuca apresentou, como característica, o padrão de incorporação a partir de um pequeno grupo de proprietários de terra em associação a um grupo reduzido de empresas, caracterizando o quadro presente. $\mathrm{O}$ bairro, composto, em grande parte, por condomínios fechados, característico pela promessa do modo de vida entre iguais e protegidos das mazelas da cidade, teve como resultado, no final da década de 80 , o montante de $40 \%$ dos moradores com renda familiar superior a 20 salários mínimos (COSENTINO, 2015). A consolidação do bairro, como frente de expansão imobiliária na cidade, teve seu ápice na proposta de emancipação em relação ao município do Rio de Janeiro.

No início da década de 90 a Barra vivia mais um momento de expansão imobiliária, capitaneado pelo orgulhoso xerife da Barra, Eduardo Paes (ex-subprefeito/ex-prefeito do Rio); a região foi cenário de limpeza, por meio da Caravana da Legalidade. A lista das comunidades que seriam removidas contava também com a Vila Autódromo, contudo, apesar de os maiores proprietários da Barra da Tijuca possuírem acusações de grilagem de terra devoluta, eles patrocinaram, explicitamente, a remoção de invasores, por intermédio da Associação Comercial e Industrial da Barra (Acibarra); o discurso da prefeitura era, justamente, o de combate aos grileiros para a remoção de diversas comunidades na época (COSENTINO, 2015).

A Vila Autódromo, localizada na esquina da Avenida Salvador Allende com a Avenida Abelardo Bueno, está no centro de todos os interesses que envolveram a construção do Centro Metropolitano e das instalações olímpicas. As famílias ocupam uma área ao lado do antigo Autódromo de Jacarepaguá, onde foi erguido o Parque Olímpico. Os moradores da Vila, tratados como invasores pelos veículos de comunicação da cidade, de fato, não só invadem o espaço dos interesses da coalizão (incorporadores, construto- 
res, rentistas, etc.) que, por sua vez, vendem a cidade como mercadoria, como também têm o desejo negado, costumeiramente, há pelo menos duas décadas, de fazer valer o seu direito à cidade.

Contrariamente às ordens de remoção da Vila Autódromo pela prefeitura do Rio de Janeiro, que se encontravam na minuta preliminar, conforme o item 5.2.1 do edital de licitação da PPP, o projeto vencedor do Concurso Internacional Parque Olímpico Rio 2016, promovido pelo Instituto de Arquitetos do Brasil - IAB - e pelo escritório de arquitetura inglês Aecom, mantinha a presença da Vila Autódromo na região. O projeto ainda previa como legado dos Jogos a urbanização da Vila, porém a prefeitura insistiu na remoção da comunidade para um condomínio do programa federal Minha Casa Minha Vida, chamado Parque Carioca. Além da coação sofrida por parte da prefeitura e das grandes incorporadoras, a comunidade também sofreu com a pressão da imprensa, como se observa nos apontamentos de Cosentino (2015):

[...] o jornal O Globo destacou em sua manchete de capa no dia 5 de outubro de 2011: "Após o rock, Rio removerá favela para as Olimpíadas" e na página 12: "Vila Autódromo na reta final". Segundo o editorial do jornal do dia 6 de outubro, a Copa do Mundo e as Olimpíadas seriam "a chance de o Rio enfrentar desafios impostos pela ocupação anárquica". E ainda o quadro opinativo da matéria trazia as seguintes informações "ALERTA: A acertada decisão de remover a Vila Autódromo, na Barra, atende a interesses urbanísticos da cidade e a compromissos do Rio com a realização dos Jogos Olímpicos". E completa afirmando que a política de remoção contrariaria conhecidos interesses políticos e ideológicos e especulativos da indústria de ocupações ilegais, e não resultados do déficit habitacional que faz com que os trabalhadores construam sua própria moradia em toda a cidade, da qual a Barra faz parte (COSENTINO, 2015, p. 125).

A Vila Autódromo não só tentou resistir às pressões, por meio da Associação de Moradores, bem como criou o seu próprio Plano Popular de Urbanização, ao buscar a permanência das famílias no seu local de direito. Para tanto, contou com a assessoria do Laboratório Estado, Trabalho, Território e Natureza (Ettern), do Instituto de Pesquisa e Planejamento Urbano e Regional (Ippur), da UFRJ, e do Núcleo de Estudos e Projetos Habitacionais e Urbanos (Nephu), da UFF.

A origem e o processo de elaboração desse plano popular surgiram de uma reunião da Associação de Moradores com o ex-prefeito Eduardo Paes, que autorizava a permanência da comunidade no mesmo local na condição de uma proposta alternativa à fornecida pela prefeitura. Assim, lançado no dia 16 de agosto de 2012, o Plano Popular da Vila Autódromo, entregue a Eduardo Paes, comprovava que a urbanização da Vila era a opção mais vantajosa para os cofres públicos do que o despejo dos moradores.

O Plano Popular estava orçado em R\$13,5 milhões, valor que correspondia a 35\% dos R\$ 38 milhões previstos, em 2012, pela prefeitura, para o reassentamento total da comunidade, valor que até 2014 superava os R\$ 200 milhões. Ainda sobre o Plano Popular, no dia 3 de dezembro de 2013 os moradores tiveram seus esforços reconhecidos ao vencer o Urban Age Award, prêmio internacional organizado pelo Deutsch Bank e pela London School of Economics, que gratifica iniciativas criativas para as cidades. 
No entanto, as dinâmicas que vêm sendo observadas nas cidades sedes destes eventos, sobretudo no Rio de Janeiro - desde o planejamento das áreas ocupadas pelos jogos, passando pelas soluções de mobilidade urbana, localização das instalações e equipamentos de apoio e culminando com a remoção massiva de população pobre ocupante do entorno das zonas de interesse, já denuncia uma clara tendência a que os beneficiários finais dos seus legados sejam outros personagens, que não aqueles que vivenciam a cidade no seu cotidiano (BOTTURA, 2014, p. 121).

Nesse contexto, Harvey (2003, p. 113) afirma que esses são processos de "[...] acumulação via espoliação dos ativos dos mais pobres", isto é, a captura da terra transformou-se em mecanismo essencial no processo de financeirização do capitalismo. Assim, os megaprojetos, complementa o autor, unem "[...] a acumulação por espoliação com a construção da hegemonia do capital financeiro, como sempre com o apoio do Estado". Logo, Rolnik (2015) assegura que é, justamente, no período em que transcorre a designação da cidade anfitriã e a realização do evento em que expulsões e despejos forçados são características comuns dos preparativos para os megaeventos. A pesquisadora também faz a seguinte observação:

A importância que se concede à criação de uma nova imagem internacional da cidade como parte integrante da preparação dos jogos supõe a eliminação de manifestações de pobreza e subdesenvolvimento. Isso ocorre predominantemente por meio de projetos de reurbanização que dão prioridade à construção de um espaço constituído por produtos imobiliários de fácil identificação e leitura no mundo corporativo (p. 245).

A Vila Autódromo, rejeitada do Projeto Olímpico, foi cenário que perturbava as necessidades dessa tipologia de acumulação de capital. As pautas históricas e necessidades de acumulação de capital cederam lugar a um projeto estruturado a partir de um modelo de negócios imposto sobre o território, por meio de um estado de suspensão das normas e conflitos ali inscritos. Essa acumulação via espoliação dos ativos dos mais pobres permitiu o sucesso dos empreendimentos tanto do Parque Olímpico como das redondezas, garantindo a extração de renda necessária para os investidores. Dessa forma, Rolnik (2015) concluiu:

[...] favelas e conjuntos habitacionais populares estão dentre os espaços considerados esteticamente negativos e, portanto, se não forem removidos, podem receber intervenções em sua imagem. Nos Jogos Olímpicos de Atenas, por exemplo, um conjunto habitacional que resistiu à demolição foi coberto por um outdoor gigante que o escondia da via de acesso do estádio (p. 246).

Assim, como saldo total ao fim da Olímpiada do Rio 2016, apenas 20 famílias permaneceram na Vila Autódromo, destacando-se que no ano de 2014 encontrava-se na Vila um total de 600 famílias, com 3.000 pessoas residentes, aproximadamente.

Isso posto, pode-se concluir que a mudança de postura do COI, ao espetacularizar as Olimpíadas e superestimar os legados obtidos com a sua promoção, incitou a competitividade entre as cidades candidatas a sediar os Jogos. Para ganhar o bônus da realização do megaevento, contudo, todos os custos para a sua execução (ônus) foram delegados às cidades anfitriãs, o que estimulou as coalizações de interesses entre os agentes econômicos que querem fazer do processo de planejamento urbano para os Jogos Olímpicos uma máquina de produzir riquezas. 
A especulação imobiliária engendrada na Barra da Tijuca com a realização da Olimpíada acirrou a disputa entre moradores e comerciantes locais, proprietários de terra, mídia, empreiteiras e órgãos públicos, contudo a presença da Vila Autódromo no caminho do desenvolvimento urbano fortalecido pelos Jogos ameaçava a sinergia de interesses entre os setores público e privado.

Enquanto a prefeitura do Rio de Janeiro se utilizou do legado que poderia obter com a Olimpíada para justificar as remoções dos moradores da Vila Autódromo, a imprensa aproveitou a ocasião para acusar a comunidade por invasão e grilagem de terra. Assim, processos de gentrificação e espoliação foram usados para garantir os interesses da coalizão entre incorporadores, construtores, rentistas e outros.

Como legado do megaevento promovido na cidade do Rio de Janeiro, para os Jogos Olímpicos 2016, a prefeitura, o governo do Estado e a União tiveram de arcar com boa parte dos custos envolvidos nas obras exigidas pelo COI, isto é, com as instalações esportivas, o alojamento e o transporte urbano. Também foi necessário realizar gastos com segurança e construção de equipamentos urbanos. Por sua vez, o legado deixado à Vila Autódromo com a promoção do megaevento na Barra da Tijuca foi o impacto na liberdade civil dos moradores locais e no direito deles à cidade.

\section{CONSIDERAÇÕES FINAIS}

Ultimamente, no âmbito das discussões sobre planejamento estratégico, vem-se notando a substituição da questão urbana pela competitividade urbana, uma vez que as cidades são pensadas como mercadorias e, portanto, são precificadas e negociadas no mercado. Assim, no comércio internacional, é a demanda de localizações pelo grande capital que qualifica a cidade como mercadoria. Entre os atributos urbanos valorizados pelo capital transnacional têm-se: os centros de convenções e exposições; os equipamentos culturais, esportivos e de lazer; os parques industriais e tecnológicos; a infraestrutura de informação, comunicação e segurança; entre outros.

Enquanto a pobreza e a marginalização afetam o entorno dos possíveis locais negociáveis das cidades, visto que comprometem a especulação do capital imobiliário; o marketing urbano torna-se ferramenta importante para a renovação de áreas centrais urbanas e para a promoção de megaeventos, ambos necessários à alteração da posição das cidades em escala global e a sua transformação em máquinas de produzir riquezas.

A realização de eventos esportivos, tais como a Copa do Mundo e as Olimpíadas, é uma forma de fazer os proprietários fundiários, os políticos locais, a mídia, as agências de serviços públicos, os setores sindicais, as instituições culturais, as equipes esportivas e os comerciantes ganharem com o crescimento urbano. Para tanto, o uso de processos de gentrificação e de espoliação são muito comuns, uma vez que eles promovem o retorno das camadas mais influentes ao coração das cidades.

Nos primeiros Jogos Olímpicos da Era Moderna foram criados os elementos simbólicos do olimpismo pelo COI não só para associá-los aos sentimentos de paz e união dos Jogos da Grécia Antiga, mas também para valorizar a marca olímpica no mercado. Assim, com o amadurecimento e a valorização do capital simbólico associado às Olímpiadas, percebeu-se o seguinte: (i) o potencial político e econômico do megaevento na produção da cidade; (ii) os possíveis benefícios decorrentes da disputa entre os gover- 
nantes para sediar as Olimpíadas e (iii) a mobilização de capitais engendrada da construção de equipamentos esportivos, urbanos e televisivos para a espetacularização do megaevento.

A responsabilidade de promover as Olímpiadas não recai mais sobre o COI, mas sobre as cidades que se candidatam para sediar os Jogos, a fim de se beneficiarem de possíveis legados. Assim, o megaevento serve não só para valorizar determinados espaços urbanos e favorecer as coalizões entre as diferentes classes sociais, bem como para satisfazer a demanda de seu principal mercado, ou seja, o capital internacional, os visitantes e os usuários solventes. Desse modo, esse modelo de cidade aumenta a desigualdade e compromete as receitas públicas e as políticas sociais, o que estimula os conflitos entre os habitantes.

A ideia de legado deixado à população pela realização dos megaeventos esportivos (Copa do Mundo/Olimpíada) é uma forma de atrair a candidatura das cidades anfitriãs, que não apenas se submetem às exigências técnicas dos padrões normativos internacionais, como também apostam na concepção de projetos arquitetônicos que interfiram no espaço urbano.

Nesse contexto, alianças entre o capital imobiliário e a gestão urbana local são estabelecidas para fazer das cidades máquinas de crescimento. Para tanto, os prefeitos não só vendem à sociedade a ideia de desenvolvimento urbano engendrado da realização de empreendimentos específicos que atendam às necessidades dos megaeventos, como asseguram um benefício coletivo decorrente da promoção desses grandes projetos urbanos, culturais e esportivos. Assim, as coalizações formadas no âmbito das redes de crescimento anseiam por dinamizar a economia local e redefinir a posição da cidade-sede no cenário mundial, por meio da valorização imobiliária obtida com a promoção desses eventos.

Em 2009 o COI elegeu o Rio de Janeiro para sediar a Olimpíada de 2016. As obras previstas concentraram-se em intervenções urbanísticas exigidas pelo COI, isto é, instalações esportivas, alojamento e transporte urbano, além da necessidade de intensificar a segurança. É importante ressaltar que a maioria das obras realizadas no Rio de Janeiro para a Olimpíada teve financiamento público, seja da prefeitura, do governo do Estado ou da União, porém muitas delas tiveram a participação de Parcerias Público-Privadas (PPP).

A Vila Autódromo, localizada na esquina da Avenida Salvador Allende com a Avenida Abelardo Bueno, está no centro de todos os interesses que envolveram a construção do Centro Metropolitano e das instalações olímpicas. As famílias ocupam uma área ao lado do antigo Autódromo de Jacarepaguá, onde foi erguido o Parque Olímpico. Os moradores da Vila, tratados como invasores pelos veículos de comunicação da cidade, de fato, não só invadem o espaço dos interesses da coalizão (incorporadores, construtores, rentistas, etc.) que, por sua vez, vendem a cidade como mercadoria, como também têm o desejo negado, costumeiramente, há pelo menos duas décadas, de fazer valer o seu direito à cidade.

Contrariamente às ordens de remoção da Vila Autódromo pela prefeitura do Rio de Janeiro, o projeto vencedor do Concurso Internacional Parque Olímpico Rio 2016 mantinha a presença da Vila Autódromo na região. O projeto ainda previa como legado 
dos Jogos a urbanização da Vila, porém além da coação sofrida pela prefeitura e pelas grandes incorporadoras para remoção da comunidade, a Vila Autódromo também sofreu com a pressão da imprensa.

Nesse contexto, ao invés de serem beneficiados com o desenvolvimento urbano promovido pelos Jogos Olímpicos no Rio de Janeiro em 2016, os moradores da Vila Autódromo sofreram com ações de remoção, por estarem em uma região que era o centro das coalizações de interesses da expansão imobiliária obtida com o megaevento, o que resultou não só na expulsão de aproximadamente 580 famílias do local, bem como na perda de liberdade civil dos moradores locais e no direito deles à cidade.

\section{REFERÊNCIAS}

ARANTES, O. B. F. Uma estratégia fatal: a cultura nas novas gestões urbanas. In: ARANTES, O. B. F.; VAINER, C. B.; MARICATO, E. A cidade do pensamento único: desmanchando consensos. 6. ed. Petrópolis: Vozes, 2011.

BOTTURA, A. C. L. O paradigma da cidade global e as olimpíadas do Rio de Janeiro. Oculum Ensaios, v. 11, n. 1, 2014.

COSENTINO, R. Barra da Tijuca: o novo Rio do capital. Rio de Janeiro: Instituto de Pesquisa e Planejamento Urbano e Regional, 2015.

COSTA, M. F. T. Cidade-mercadoria, comunicação e consumo. Contemporânea, ed. 16, v. 8, n. 3, p. 145160, 2010.

FERREIRA, J. S. W. O mito da sociedade global. O papel da ideologia na produção do espaço urbano. Petrópolis: Ed. Vozes; São Paulo: Editora Unesp, 2007.

GOTTDIENER, M. A produção social do espaço urbano. 2. ed. São Paulo: Edusp, 1997.

HARVEY, D. O novo imperialismo. São Paulo: Loyola, 2003.

KOWARICK, L. Escritos urbanos. São Paulo: Ed. 34, 2000.

LIMA, C. R.; TAKAKI, K. E.; SOUSA COLANTUONO, A. C. Possíveis impactos socioeconômicos das Olimpíadas de 2016 no Rio de Janeiro. Getec, v. 5, n. 10, 2016.

LIRA, T. E. A Paixão nos Une? A identidade brasileira e a estratégia da candidatura do Rio de Janeiro aos Jogos Olímpicos de 2016. Revista de Estudos Internacionais, v. 1, n. 1, p. 112-127, 2010.

LOGAN, J. R.; MOLOTCH, H. L. The city as a growth machine. In: Urban Fortunes: the political economy of place. Berkeley and Los Angeles: University of Califórnia Press, 1987.

MARICATO, E. Cidades no Brasil: neo desenvolvimentismo ou crescimento periférico? In: MARICATO, E.; MIRANDA, H. Como enfrentar a crise das cidades? Política Social e Desenvolvimento, n. 1, ano 1, nov. 2013.

MASCARENHAS, G. Cidade mercadoria, cidade-vitrine, cidade turística: a espetacularização do urbano nos megaeventos esportivos. Caderno Virtual de Turismo, Edição especial: Hospitalidade e Políticas Públicas em Turismo, Rio de Janeiro, v. 14, supl. 1, p. 52-65, nov. 2014.

MEGAEVENTOS: Comunidades cariocas sofrem com o processo de espoliação urbana. Observatório das Metrópoles. Rio de Janeiro, 30 jun. 2011. Disponível em: <http://www.observatoriodasmetropoles. net/index.php?option $=$ com_content $\&$ view=article \&id=1706\%3Aentrevista-comunidades-cariocas-sofrem-com-o-processo-de-espoliacao-urbana\&catid=43\%3Anoticias\&ltemid=114\&lang=pt $>$. Acesso em: 17 jun. 2015.

OLIVEIRA, N. G. O poder dos jogos e os jogos de poder: os interesses em campo na produção de uma cidade para o espetáculo esportivo. 2012. Tese (Doutorado em Planejamento Urbano e Regional) - UFRJ, Rio de Janeiro, 2012.

PRONI, M. W.; FAUSTINO, R. B.; SILVA, L. O. Impactos econômicos de megaeventos esportivos. Belo Horizonte: Casa da Educação Física, 2014.

ROLNIK, R. Guerra dos lugares. São Paulo: Boitempo, 2015.

SÁNCHEZ, F. A reinvenção das cidades para um mercado mundial. 2. ed. Chapecó: Argos, 2010.

VAINER, C. B. Utopias urbanas e o desafio democrático. Revista Paranaense de Desenvolvimento, Curitiba, n. 105, p. 25-31, jul./dez. 2003.

Pátria, empresa e mercadoria: notas sobre a estratégia discursiva do planejamento estratégico urbano. In: ARANTES, O. B. F.; VAINER, C. B.; MARICATO, E. A cidade do pensamento único: desmanchando consensos. 6. ed. Petrópolis: Vozes, 2011. 